\title{
UCRL-PROC-216002
}

LAWRENCE LIVERMORE NATIONAL LABORATORY

\section{Grazing Incidence Pumping for High Efficiency X-ray Lasers}

J. Dunn, R. Keenan and V.N. Shlyaptsev

October 3, 2005

SPIE - International Society for Optical Engineering conference on Soft X-ray Lasers and Applications VI, San Diego, CA, August 2 - 3, 2005

Vol. 5919 


\section{Disclaimer}

This document was prepared as an account of work sponsored by an agency of the United States Government. Neither the United States Government nor the University of California nor any of their employees, makes any warranty, express or implied, or assumes any legal liability or responsibility for the accuracy, completeness, or usefulness of any information, apparatus, product, or process disclosed, or represents that its use would not infringe privately owned rights. Reference herein to any specific commercial product, process, or service by trade name, trademark, manufacturer, or otherwise, does not necessarily constitute or imply its endorsement, recommendation, or favoring by the United States Government or the University of California. The views and opinions of authors expressed herein do not necessarily state or reflect those of the United States Government or the University of California, and shall not be used for advertising or product endorsement purposes. 


\title{
Grazing Incidence Pumping for High Efficiency X-ray Lasers
}

\author{
J. Dunn ${ }^{1}$, R. Keenan ${ }^{1}$, and V.N. Shlyaptsev ${ }^{2}$ \\ ${ }^{1}$ Lawrence Livermore National Laboratory, Livermore, CA 94551 \\ 2 Dept. of Applied Science, University of California Davis-Livermore, Livermore, CA 94551
}

\begin{abstract}
Over the last decade, most laser-driven collisional excitation x-ray lasers have relied on the absorption of the pump energy incident at normal incidence to a pre-formed plasma. The main advantage is that the inversion can be created at various plasma regions in space and time where the amplification and ray propagation processes are best served. The main disadvantage is that different plasma regions regardless of the contribution to the inversion have to be pumped simultaneously in order to make the laser work. This leads to a loss of efficiency. The new scheme of grazing incidence pumping (GRIP) addresses this issue. In essence, a chosen electron density region of a pre-formed plasma column, produced by a longer pulse at normal incidence onto a slab target, is selectively pumped by focusing a short pulse of $100 \mathrm{fs}-10 \mathrm{ps}$ duration laser at a determined grazing incidence angle to the target surface. The exact angle is dependent on the pump wavelength and relates to refraction of the drive beam in the plasma. The controlled use of refraction of the pumping laser in the plasma results in several benefits: The pump laser path length is longer and there is an increase in the laser absorption in the gain region for creating a collisional Ni-like ion x-ray laser. There is also an inherent traveling wave, close to $c$, that increases the overall pumping efficiency. This can lead to a $3-30$ times reduction in the pump energy for mid-Z, sub-20 nm lasers. We report several examples of this new $\mathrm{x}$-ray laser on two different laser systems. The first demonstrates a 10 $\mathrm{Hz}$ x-ray laser operating at $18.9 \mathrm{~nm}$ pumped with a total of $150 \mathrm{~mJ}$ of $800 \mathrm{~nm}$ wavelength from a Ti:Sapphire laser. The second case is shown where the COMET laser is used both at $527 \mathrm{~nm}$ and $1054 \mathrm{~nm}$ wavelength to pump higher $\mathrm{Z}$ materials with the goal of extending the wavelength regime of tabletop $\mathrm{x}$-ray lasers below $10 \mathrm{~nm}$.
\end{abstract}

Keywords: x-ray laser, laser-driven plasmas, grazing incidence pumping, short pulse lasers

\section{INTRODUCTION}

A long-term goal of $\mathrm{x}$-ray laser research over the last two decades has been to produce efficient $\mathrm{x}$-ray laser output with progressively lower sub-joule laser pump energies to achieve useable sub-20 nm wavelength soft $\mathrm{x}$-ray or Extreme Ultra Violet (EUV) output energy at high repetition rates. In recent years a number of different approaches have been tried with lasing demonstrated on the collisional excitation Ni-like Mo ion $4 d^{1} \mathrm{~S}_{0}-4 p{ }^{1} \mathrm{P}_{1}$ laser at $18.9 \mathrm{~nm}$ wavelength with small pump energies. Two groups, in China and Japan, achieved lasing using the short pulse longitudinal pumping geometry with pre-formed plasmas from laser-irradiated Mo capillaries or flat Mo slabs [1,2]. One of these experiments had an interesting characteristic of a sub-milliradian highly directional beam for the x-ray laser line [2]. The Max Planck group at Garching reported lasing on the Ni-like Mo $18.9 \mathrm{~nm}$ line, the $4 f^{1} \mathrm{P}_{1}-4 d{ }^{1} \mathrm{P}_{1}$ laser at $22.6 \mathrm{~nm}$ as well as the Ne-like Ti $3 p{ }^{1} \mathrm{~S}_{0}-3 s{ }^{1} \mathrm{P}_{1}$ line at $32.6 \mathrm{~nm}$ [3]. In this instance the short pulse beam was incident at an angle of $30^{\circ}$ relative to the target surface. Earlier work at longer wavelengths, above $20 \mathrm{~nm}$, has also been demonstrated. The capillary discharge $\mathrm{x}$ ray laser at Colorado State University and elsewhere has been developed to a high degree with both high repetition rates and strong $\sim \mathrm{mJ}$ output on the Ne-like Ar $46.9 \mathrm{~nm}$ line [4]. The ultrafast pumped optical field ionization (OFI) mechanism has been successfully shown for Pd-like Xe at $41.8 \mathrm{~nm}$ [5]. This was recently repeated by the LOA group in gain saturation regime for both the Pd-like Xe line [6] and the Ni-like $\mathrm{Kr}$ line at $32.8 \mathrm{~nm}$ [7]. A recent advance has been the use of higher order harmonics to seed the $32.8 \mathrm{~nm}$ OFI laser to boost the output and improve the $\mathrm{x}$-ray laser characteristics [8].

We reported at the last Soft X-ray Lasers and Applications $V$ meeting a new geometry called grazing incidence pumping (GRIP) for improving the coupling efficiency of laser energy into a pre-formed plasma [9, 10]. The main 
objective was to achieve a sub-20 nm x-ray laser with substantial single-shot output, with determined parameters of amplified spontaneous emission small signal gain, operating at a high repetition rate using a small input energy of $\sim 150$ $\mathrm{mJ} / \mathrm{shot}$. We will review the main advantages of the GRIP x-ray laser as well as the results from recent experiments at different laser pump wavelengths.

\section{GRAZING INCIDENCE PUMPING GEOMETRY}

Normal incidence laser irradiation or transverse pumping has been the main stay of laser-driven x-ray lasers and widely employed since the beginning of laboratory $\mathrm{x}$-ray lasers. The main advantage is that the laser energy is absorbed at various plasma regions perpendicular to the target in space and time up to the critical surface associated with the laser pump wavelength. The amplified spontaneous emission is optimized in the plasma column when and where the gain is simultaneously high with good $\mathrm{x}$-ray propagation. For the mid-Z Ni-like ion lasers like $\mathrm{Pd}$, this has been recently determined through near-field imaging and x-ray laser interferometry techniques as occurring in the $\sim 2 \times 10^{20} \mathrm{~cm}^{-3}$ region when the plasma density gradients have been relaxed [11]. The use of a prepulse or a long nanosecond pulse to form the plasma followed by a more intense main pulse or picosecond pulse to produce the inversion is important $[12,13]$. The main disadvantage of the normal incidence pumping is that substantial plasma regions regardless of the net contribution to the inversion have to be heated simultaneously in order to make the laser work. This leads to a loss of efficiency and not the best use of the available pumping energy. Longitudinal schemes have a number of appealing characteristics and have been utilized in collisional excitation and recombination lasers $[1,2,6,14]$. The main advantages are the ability to create high irradiance short pulse pumping inside a capillary, for instance, where the electron density profile has been tailored. High laser absorption achieved in millimeter plasma lengths and co-propagation of the $\mathrm{x}$-ray laser along with the pump pulse at the speed of light are very desirable. However, the strong absorption of the laser drive begins to place restrictions on the density of longer plasmas that makes pumping x-ray lasers at sub-20 $\mathrm{nm}$ wavelengths more challenging.

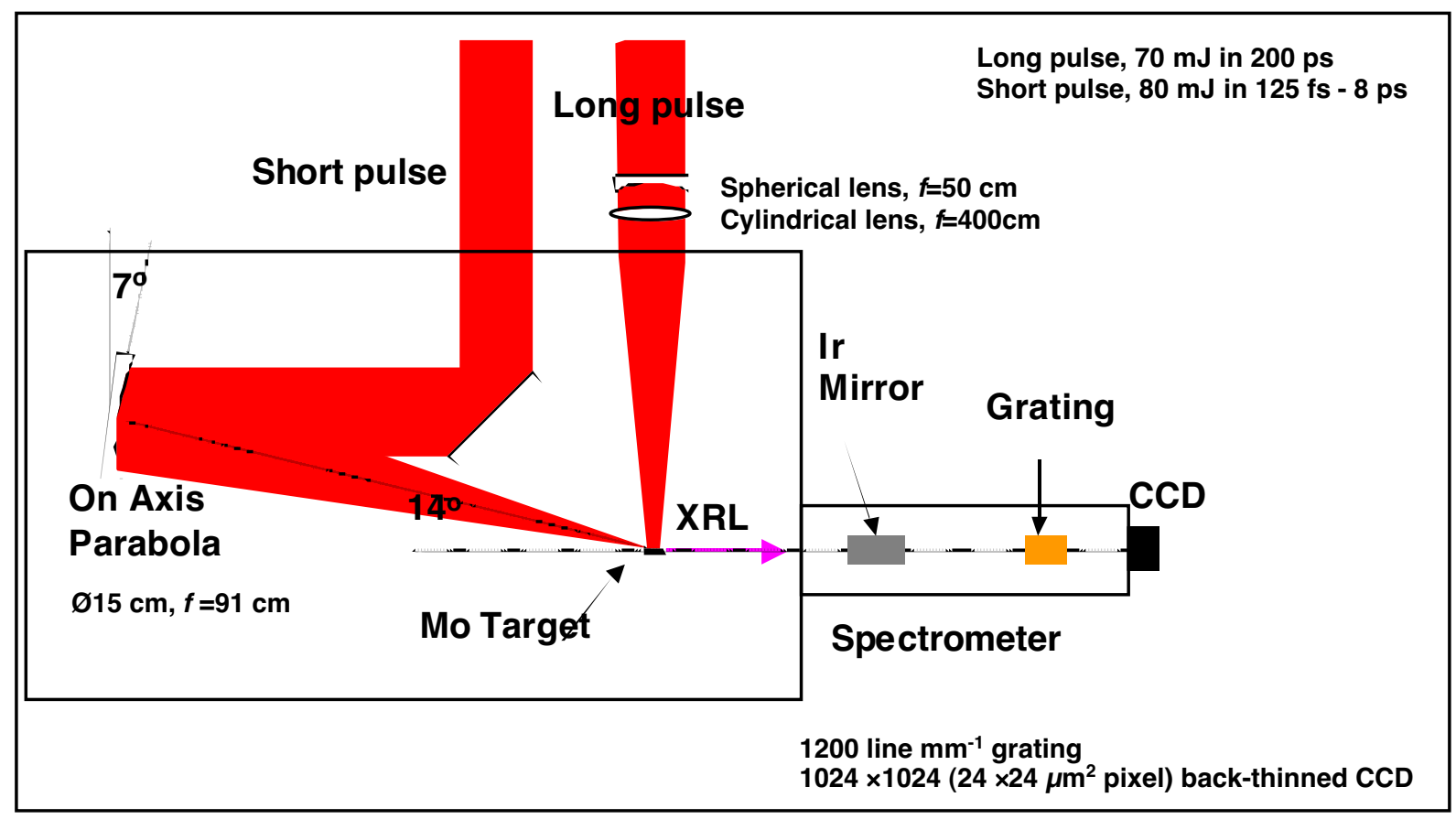

Figure 1:Diagram showing experimental setup for grazing incidence pumping scheme for 800 nm wavelength laser. Preformed plasma is first generated by 200 ps laser pulse focused in a line at normal incidence on a solid target. Second pulse produces inversion process at grazing incidence angle chosen to preferentially pump a specific density region where the gain will be optimum. In this case $14^{\circ}$ angle was chosen to pump Ni-like Mo $18.9 \mathrm{~nm}$ laser. The x-ray laser is produced close to on-axis and is measured with a flat field variable spaced grating spectrometer. 
The new scheme of grazing incidence pumping addresses some of the issues associated with the geometries described above by using the refraction of the laser drive in the plasma to select a specific gain region where the $\mathrm{x}$-ray laser will be generated and enhanced. Figure 1 shows the experimental pumping geometry. Like many of the previous schemes the $\mathrm{x}$ ray laser is produced in two stages. A pre-formed plasma is generated by irradiating the target with a long 200 ps laser pulse at normal incidence. The plasma is allowed to evolve in time to allow the electron density gradients relax. The short pulse then irradiates the plasma column at a shallow angle to the target hence the name grazing incidence. This angle is chosen to allow the laser to be absorbed within the plasma up to a maximum density within the gain region $\mathrm{n}_{\mathrm{e} 0}$. Refraction turns the laser at this density, thus allowing the optimization of a particular x-ray laser based on atomic kinetics considerations as well as refraction and propagation of the $\mathrm{x}$-ray laser itself. For a maximum density within the gain region $\mathrm{n}_{\mathrm{e} 0}$ and the critical density $\mathrm{n}_{\mathrm{cr}}$ for the optical pump beam of wavelength $\lambda$ the required angle of incidence is obtained from $\phi_{r}=\sqrt{ } n_{e 0} / n_{c r}$ which is a simplification of the refraction equation. For example, in our first experimental investigation on the $18.9 \mathrm{~nm}$ Ni-like Mo laser using the $10 \mathrm{~Hz}$ LLNL Callisto Ti:Sapphire laser a maximum density of $\mathrm{n}_{\mathrm{e} 0}=1 \times 10^{20} \mathrm{~cm}^{-3}$ for the gain region and the critical density for the $800 \mathrm{~nm}$ optical pump of $\mathrm{n}_{\mathrm{ec}}=1.74 \times 10^{21} \mathrm{~cm}^{-3}$ dictated the GRIP angle of incidence $\phi_{r}=13.7^{\circ}[9,15]$. Strong lasing has been observed by the Colorado State University group on Ni-like Mo with this grazing angle [16]. The turning point limits the direct heating of the plasma to densities well below the critical density. This is preferred for this specific Mo laser and is a major advantage over the transverse pumping geometry. The refracted laser beam is turned away from the target where further absorption and heating of the gain region can occur as the beam exits the plasma column. The main advantages are that the grazing incidence gives a longer path length and higher absorption in the lower density region where the amplification takes place. The traveling wave close to the speed of light is inherent to the pumping geometry and there is no restriction in the target length due to absorption. The latter is of concern in the longitudinal pumping geometry where all of the laser energy required for the full plasma column has to be propagated through the initial parts of the plasma. The RADEX simulation code [17] predicts that the absorption in the gain region can be increased from $5-8 \%$ for transverse pumping to as high as $50-$ $70 \%$ for the GRIP geometry [9, 10]. To illustrate the increased absorption, Fig. 2 shows the predicted electron

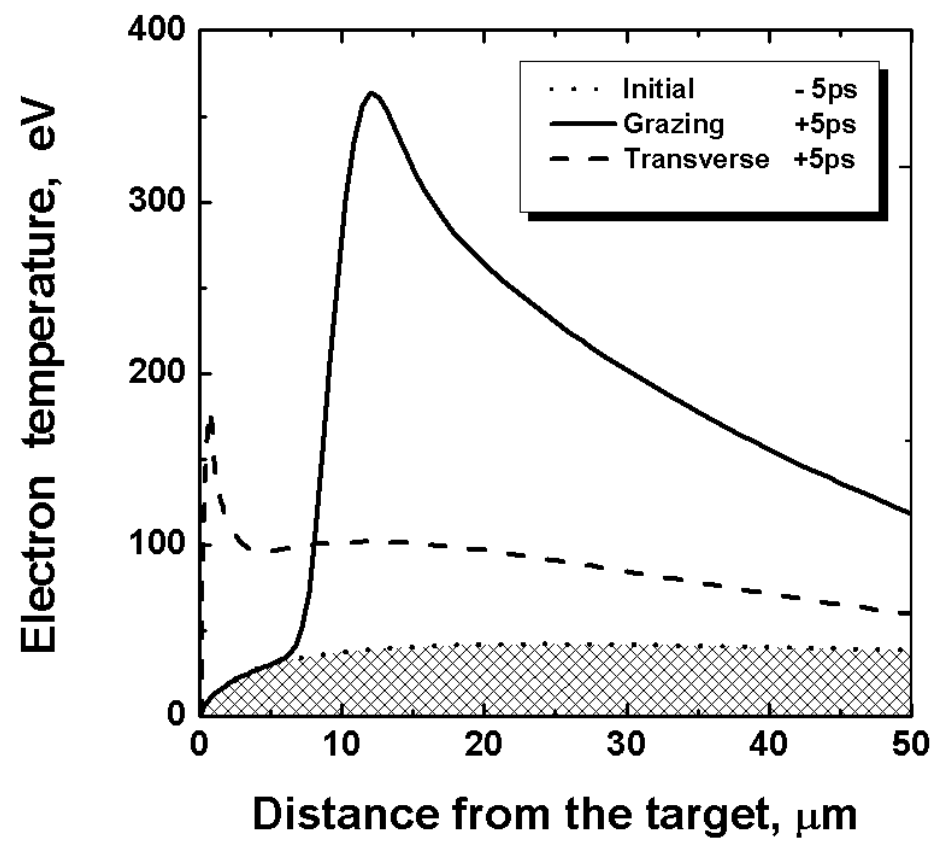

Figure 2: RADEX simulations show electron temperature, $T_{e}$, profile of a Mo plasma. All times are relative to a delay of $\Delta t=$ 500 ps after the peak of the 200 ps plasma-forming beam at normal incidence. Dotted line at -5 ps shows initial conditions before arrival of $4 \mathrm{ps}$ short pulse. $\mathrm{T}_{\mathrm{e}}$ conditions are shown at $+5 \mathrm{ps}$ for the grazing incidence pumping case (solid line) at an angle of $14^{\circ}$ relative to the surface and normal incidence (transverse) case (dashed line).

temperature from the RADEX code for the short pulse excitation in transverse and grazing incidence pumping cases for a Mo plasma. The plasma is generated with a $\sim 60-80 \mathrm{~mJ}$ energy, in a $200 \mathrm{ps}$ (FWHM) laser pulse focused at normal incidence at an irradiance of $\sim 2 \times 10^{11} \mathrm{~W} \mathrm{~cm}^{-2}$. The optimum delay for firing the short 4 ps laser pulse was predicted to be $\Delta \mathrm{t}=500 \mathrm{ps}$ for these conditions where $\mathrm{T}_{\mathrm{e}}$ reaches $50 \mathrm{eV}$. The $10^{20} \mathrm{~cm}^{-3}$ density region occurs at $\sim 16 \mu \mathrm{m}$ from the 
target surface. The grazing incidence pumping laser is focused with $\sim 60-80 \mathrm{~mJ}$ energy in a 4 ps pulse at $14^{\circ}$, corresponding to $\sim 2 \times 10^{13} \mathrm{~W} \mathrm{~cm}^{-2}$, and shows substantial enhancement raising the temperature to $200-300 \mathrm{eV}$ at the predicted gain region. On the normal incidence pumping at the same laser irradiance, the temperatures are overall lower with local heating occurring at the critical density close to the target surface.

\section{EXPERIMENTAL RESULTS}

The experiment to produce a $10 \mathrm{~Hz}$, Ni-like Mo $18.9 \mathrm{~nm}$ x-ray laser, Fig.1, was conducted on the $800 \mathrm{~nm}$ wavelength Callisto (JANUSP) laser at the Lawrence Livermore National Laboratory [9, 15]. The grazing incidence angle was chosen to be $14^{\circ}$ to pump the turning point electron density of $10^{20} \mathrm{~cm}^{-3}$. An on-axis parabola with focal length of 91 $\mathrm{cm}$ was inclined at an angle of $7^{\circ}$ to the short pulse beam to produce a short line focus of $25-30 \mu \mathrm{m}(\mathrm{FWHM}) \times 0.4 \mathrm{~cm}$ long on a flat, polished Mo slab. The pulse duration could be varied from 125 fs to 8 ps and the maximum laser energy delivered on target was $\sim 80 \mathrm{~mJ}$. The long 200 ps pulse was focused to a line $0.5 \mathrm{~cm}$ in length using a combination of a spherical lens, $f=50 \mathrm{~cm}$, and a cylindrical lens, $f=400 \mathrm{~cm}$. The maximum energy available in this beam was $\sim 60-70$ $\mathrm{mJ}$. The best lasing results for this experiment were achieved when a narrow line focus of $\sim 15 \mu \mathrm{m}$ (FWHM) was produced, corresponding to an irradiance of $5 \times 10^{11} \mathrm{~W} \mathrm{~cm}^{-2}$. Slab targets of various lengths from $0.1 \mathrm{~cm}$ up to $0.4 \mathrm{~cm}$ were irradiated with the two overlapped beams. The optimum x-ray laser output was observed when the delay between the two laser beams was set to $500 \mathrm{ps}$ [15]. The $18.9 \mathrm{~nm} 4 d-4 p$ laser line was observed to be emitted with a deflection

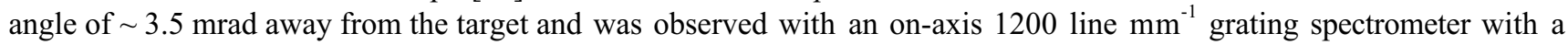
thermoelectrically cooled back-illuminated charge-coupled device (CCD) $1024 \times 1024(24 \mu \mathrm{m} \times 24 \mu \mathrm{m}$ pixel) detector. Various thicknesses of aluminum foils from $0.2-2 \mu \mathrm{m}$ were placed in front of the spectrometer to attenuate the $\mathrm{x}$-ray laser signal. In addition multilayer mirror optics were used to image the near-field pattern of the x-ray laser [18].

(a)

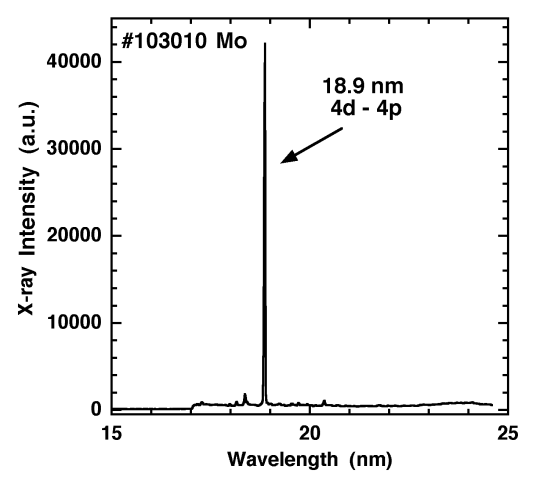

(b)

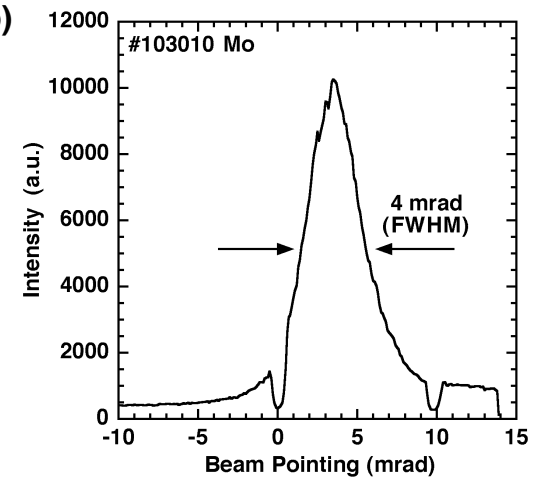

(c)

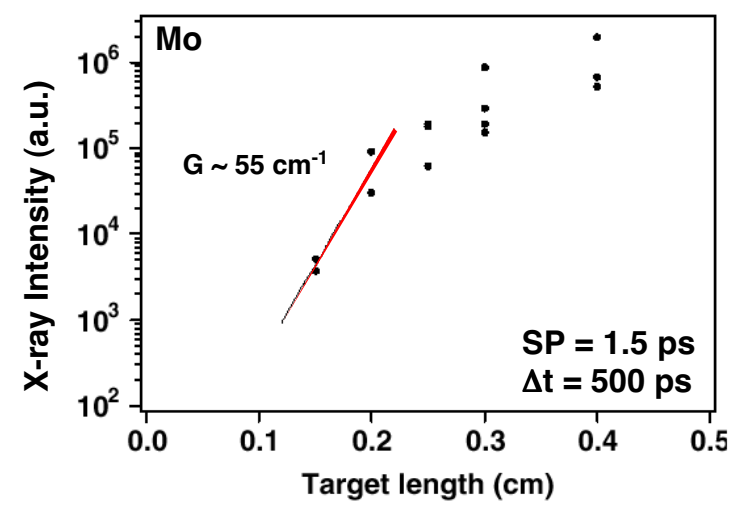

Figure 3:(a) Typical spectrum from an irradiated $0.4 \mathrm{~cm}$ Mo slab target showing strong emission from the $18.9 \mathrm{~nm} \mathrm{Ni}-\mathrm{like} \mathrm{Mo}$ laser line. (b) A lineout through the same shot indicating the horizontal beam pointing characteristics of the 18.9 $\mathrm{nm}$ x-ray laser. Beam deflection angle and divergence is $3.5 \mathrm{mrad}$ and $4 \mathrm{mrad}$ (FWHM), respectively. (c) Intensity vs length scan for Mo slab targets irradiated with $70 \mathrm{~mJ}, 200 \mathrm{ps}$ pulse followed by $1.5 \mathrm{ps}$ grazing incidence pumping beam. Time delay of $\Delta \mathrm{t}=500 \mathrm{ps}$ between the two pulses gives highest $\mathrm{x}$-ray laser output. Small signal gain is determined to be $55 \mathrm{~cm}^{-1}$. 
We summarize the results of this experiment using a total energy of $150 \mathrm{~mJ}$ focused onto the target. When the conditions were optimized as described above the x-ray laser could be observed for different short pulse durations though the shortest and longest pulses had relatively low output. The best lasing output was observed with a pulse duration of $1.5 \mathrm{ps}$ corresponding to an irradiance of $5 \times 10^{13} \mathrm{~W} \mathrm{~cm}^{-2}$ and a delay of $500 \mathrm{ps}$ between the two pulses. The $\mathrm{x}$-ray laser was observed to disappear when the laser energy in both beams was lowered by $\sim 10-15 \%$. This indicated that the laser pump conditions were just above the threshold for lasing. Figure 3(a) and (b) show a typical intensity lineout and horizontal beam directional pattern for a single-shot spectrum from a $0.4 \mathrm{~cm}$ slab target. In spite of the narrow line foci used in the experiment the x-ray laser exhibits a very uniform and symmetrical beam pattern with a small deflection angle away from the target. This is consistent with good propagation and amplification within the $\sim 5 \times 10^{19} \mathrm{~cm}^{-3}$ density region. The intensity versus length plot is displayed in Fig. 3 (c). The small signal gain is determined to be $55 \mathrm{~cm}^{-1}$ for $0.2 \mathrm{~cm}$ with a slow roll-off at longer targets. The overall GL product was estimated to be 14 and close to saturation [15].

\section{SHORT WAVELENGTH SCALING}

The experiments were repeated on the Compact Multipulse Terawatt (COMET) laser using the fundamental $1054 \mathrm{~nm}$ wavelength beam as well as the frequency doubled light for the short pulse. The main goal was to apply more energy required to study the generation of shorter wavelength $\mathrm{x}$-ray lasers. A further consideration was to increase the laser focus size to heat a larger gain volume. A final point was to investigate the $\mathrm{x}$-ray laser parameters at different laser wavelengths $527 \mathrm{~nm}, 1054 \mathrm{~nm}$ and grazing incidence angles $10^{\circ}, 13^{\circ}$ and $20^{\circ}$ for the short pulse. We briefly report a few results for $10^{\circ}$ grazing incidence for $527 \mathrm{~nm}$ laser wavelength corresponding to a turning point at $\sim 1.2 \times 10^{20} \mathrm{~cm}^{-3}$ density and will comment in detail in future publications. The COMET laser was set up to use the $600 \mathrm{ps}, 1054 \mathrm{~nm}$ laser with $1.2-1.5 \mathrm{~J}$ energy focused into a $40 \mu \mathrm{m}(\mathrm{FWHM}) \times 8 \mathrm{~mm}$ line focus at normal incidence. A $1.5 \mathrm{ps}$ short pulse beam was frequency doubled to $527 \mathrm{~nm}$ with $\sim 1.3 \mathrm{~J}$ energy in a $40 \mu \mathrm{m}(\mathrm{FWHM}) \times 7 \mathrm{~mm}$ line focus. We investigated targets of $\mathrm{Mo}, \mathrm{Pd}, \mathrm{Ag}$

(a)

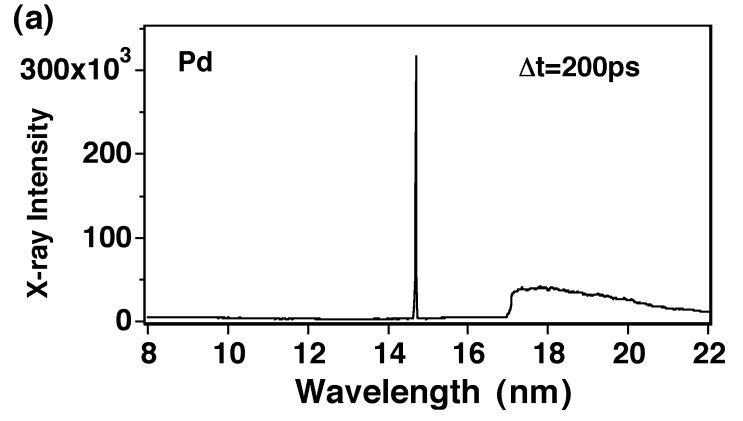

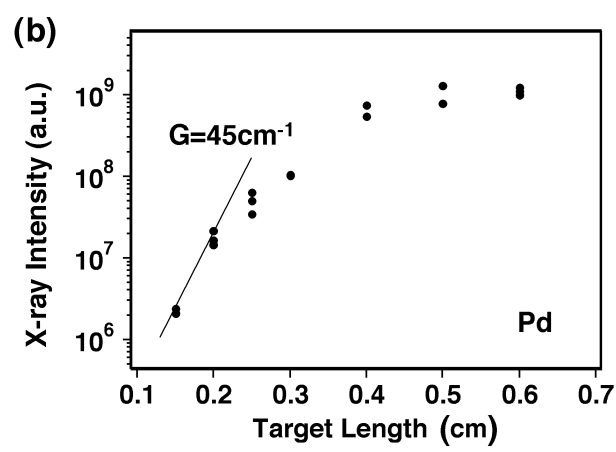

(c)

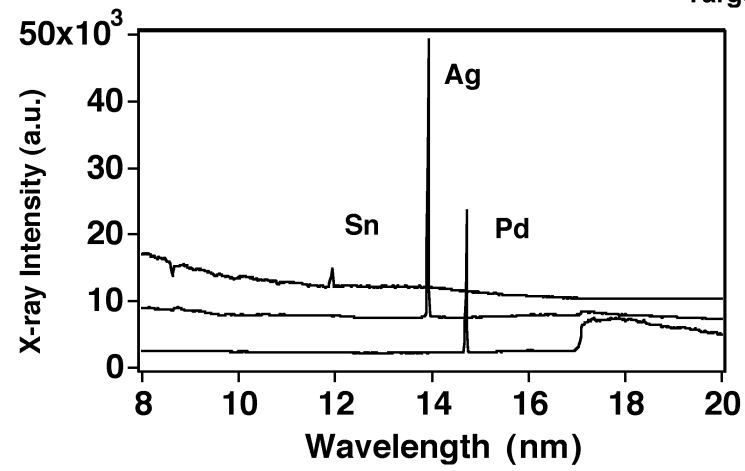

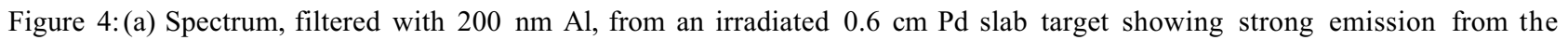
$14.7 \mathrm{~nm}$ Ni-like Pd laser line. (b) Intensity vs length scan for Pd slab targets. Time delay of $\Delta \mathrm{t}=200 \mathrm{ps}$ between the two pulses gives highest $x$-ray laser output. Small signal gain is determined to be $45 \mathrm{~cm}^{-1}$. (c) Several single shot spectra from $\mathrm{Pd}, \mathrm{Ag}$, and Sn targets showing lasing at $14.7 \mathrm{~nm}, 13.9 \mathrm{~nm}$ and $11.9 \mathrm{~nm}$ wavelength, respectively.

and Sn but concentrated mainly on the higher $\mathrm{Z}$ materials. Our initial expectation was that a four times increase in laser energy e.g. $0.6-1 \mathrm{~J}$ total energy should be sufficient to pump these longer targets. However pumping energies above $2 \mathrm{~J}$ were required. Nonetheless very strong lasing was achieved on the $\mathrm{Ag}$ and $\mathrm{Pd} 4 d-4 p$ lines at $13.9 \mathrm{~nm}$ and $14.7 \mathrm{~nm}$, respectively. The laser drive fluences on target are similar to the results reported by the Colorado group [19]. The 
optimum delay before firing the short pulse was found to be $200 \mathrm{ps}$ relative to the peak of the long pulse. Figure 4(a) shows a spectrum for a $0.6 \mathrm{~cm}$ Pd target. The x-ray laser is driven into the saturation regime and requires to be filtered with $200 \mathrm{~nm}$ of aluminum to prevent the CCD from saturating. Figure 4(b) is an intensity versus length scan for the Pd $\mathrm{x}$-ray laser showing strong exponentiation up to $0.3 \mathrm{~cm}$ targets with a small signal gain estimated to be $\sim 45 \mathrm{~cm}^{-1}$. The $\mathrm{x}$ ray laser goes into saturation in a predictable manner. Silver targets show similarly strong output as the Pd while the Sn line although lasing is considerably lower in intensity, Fig. 4(c). Note that each spectrum in Fig. 4(c) has been filtered slightly differently: Pd with $200 \mathrm{~nm} \mathrm{Al}$, Ag with $200 \mathrm{~nm}$ Lexan/75 nm Al, Sn with $300 \mathrm{~nm} \mathrm{Zr/100} \mathrm{nm} \mathrm{polyimide.}$

\section{DISCUSSION AND CONCLUSIONS}

There are a few caveats relating to the grazing incidence pumping scheme that should be mentioned. The exact parameters of the pre-pulse or plasma-forming pulse, for example duration, energy and focal conditions, have an important role to play here. This first pulse largely determines the plasma ionization, temperature and density profile conditions that can directly affect the resulting x-ray laser output characteristics. For example, the initial conditions for

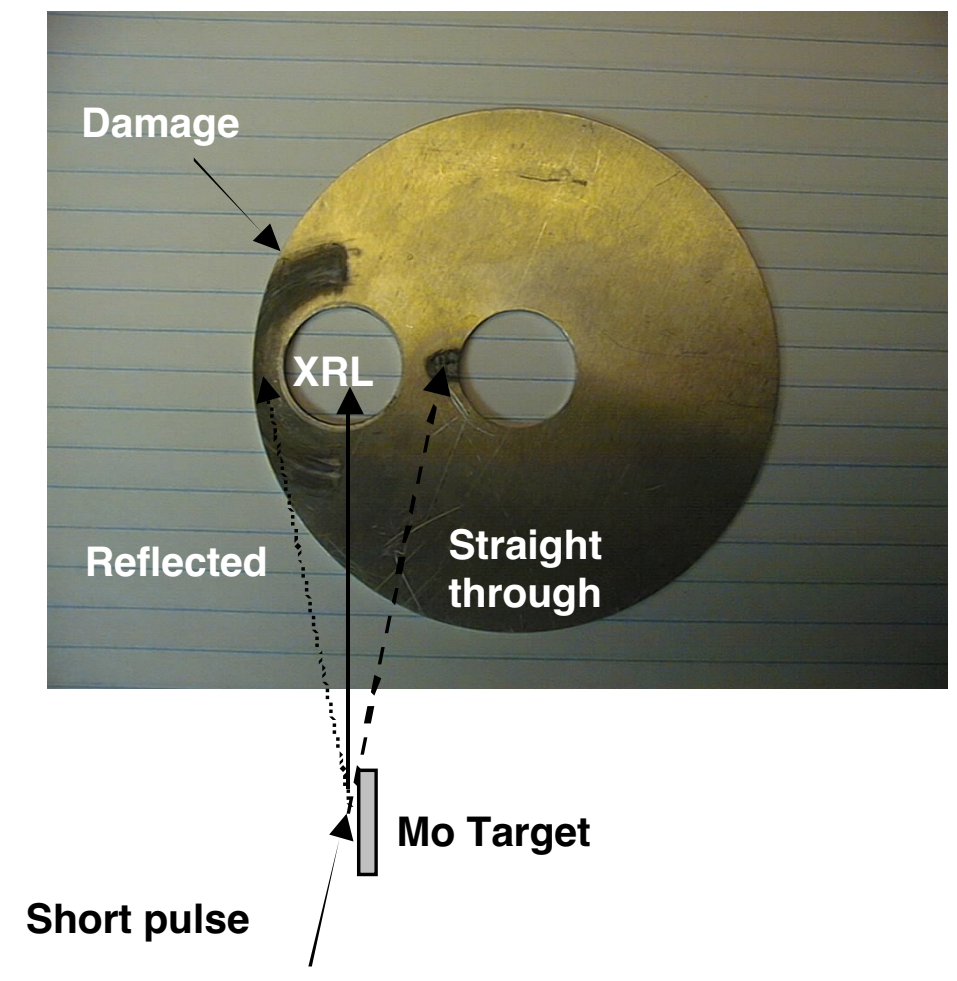

Figure 5:Blast shield used to protect filter wheel in front of the on-axis spectrometer approximately $7 \mathrm{~cm}$ from the end of the Mo target. Symmetrical damage arcs (left side of blast shield) produced by the grazing incidence short pulse laser reflected from the plasma profile are shown. The straight through laser beam (dashed line) that misses the target, the $\mathrm{x}$-ray laser direction (solid line) and the reflected laser path (dotted line) are illustrated to show the approximate geometry. The reflected energy is approximately at the same angle as the grazing incidence beam (not to scale).

two recent Mo x-ray laser GRIP experiments at a similar angle of incidence $14^{\circ}[15,16]$ can explain the difference in the optimum x-ray laser output as a function of the delay between the long pulse and short pulse. Secondly, it has always been advantageous to have a substantial fraction of the plasma in the closed shell ionization, or within a few charge states away from the closed shell, when the short pulse fires. The normal incidence short pulse, as shown in Fig. 2, heats large regions of the plasma at different distances from the target and so will pump the gain medium, e.g. the ground state of the Ni-like ion, wherever it occurs. Since the GRIP geometry is more spatially localized in the heating, the ion abundance in the selected pumped region is important and requires careful matching to enhance the x-ray laser output [18]. Finally one more area that is important for study is a detailed treatment of the laser absorption in long path lengths at these grazing incidence angles. Ideally the laser energy should be absorbed in the gain medium close to the maximum turning density rather than in the peripheral low density region, as discussed in [20]. This will maximize the laser coupling 
efficiency into the x-ray laser output. A measurement of the laser absorption in the GRIP geometry would be useful to benchmark short pulse laser energy coupling simulations for hydrodynamics codes. Figure 5 illustrates this point by showing that the laser energy not absorbed in the grazing incidence short pulse is refracted within the plasma density gradient and ultimately reflected out of the plasma in a symmetrical arc. Figure 5 shows the damage spots on the left of the blast shield placed $\sim 7 \mathrm{~cm}$ from the end of the Mo target used in the $800 \mathrm{~nm}$ experiments where the grazing angle of incidence is $14^{\circ}$. We note that there is a high degree of symmetry in the arc indicative of the plasma density profile at the turning point. The reflected angle matches the incident angle when compared to the straight through damage spot.

In conclusion, we have shown that the grazing incidence pumping geometry has a number of advantages when compared with other schemes. The short pulse energy is delivered and absorbed at a specific electron density where the gain is expected to occur. The grazing angle is chosen for the specific pump wavelength and relies on the controlled use of refraction. The grazing incidence short pulse laser beam also increases the path length and laser absorption within the gain region. The scheme has a traveling wave irradiation geometry close to $c$. Overall, this improves the laser coupling efficiency and allows smaller laser pump energies to be used. Experimental results are shown for a $10 \mathrm{~Hz} \mathrm{Ni-like} \mathrm{Mo} 18.9$ $\mathrm{nm}$ laser pumped with a total energy of $150 \mathrm{~mJ}$. The effectiveness of the grazing incidence geometry has been reported by a number of different groups at this meeting $[19,21,22]$ and it is expected to play an important part in the future development of both high repetition rate and short wavelength x-ray lasers.

The $527 \mathrm{~nm}$ grazing incidence pumping experiments on Pd, Ag and Sn clearly work although the effectiveness of different laser pump wavelengths and best choice for pumping these mid- $Z$ target plasmas warrants further study. However, this type of experiment is necessary and demonstrate that the GRIP scheme can be successfully applied under a range of different pumping angles and wavelengths. RADEX simulations predict that it should be feasible to achieve sub$10 \mathrm{~nm}$ lasing with $5-10 \mathrm{~J}$. It may take approximately $\sim 100 \mathrm{~J}$ of pump energy to generate an $\mathrm{x}$-ray laser close to the water-window e.g. Ni-like Ta $4 d-4 p$ line at $4.48 \mathrm{~nm}$.

\section{ACKNOWLEDGMENTS}

The continued support of Al Osterheld is greatly appreciated. We would like to thank a number of people: We acknowledge discussions with P. Patel and R. Smith as well as the technical contributions of D. Price, J. Boyett, R. Van Maren, C. Bruns, R. Berry and J. Hunter. Work performed under the auspices of the US Department of Energy by the University of California Lawrence Livermore National Laboratory under Contract No. W-7405-Eng-48 and in part by funding from the National Science Foundation through the Center for Biophotonics, an NSF Science and Technology Center, managed by the University of California, Davis, under Cooperative Agreement No. PHY 0120999.

\section{REFERENCES}

1. R. Li, and Z.Z. Xu, "Highly efficient transient collisional excitation x-ray laser in Ni-like Mo ions", Journal de Physique IV 11 (PR2), 27-34 (2001).

2. T. Ozaki, R. A. Ganeev, A. Ishizawa, T. Kanai, and H. Kuroda, "Highly Directive $18.9 \mathrm{~nm}$ Nickel-like Molybdenum X-Ray Laser Operating at 150 mJ Pump Energy", Phys. Rev. Lett. 89, 253902 1-4 (2002).

3. R. Tommasini, J. Nilsen and E.E. Fill, "Investigations on $10-\mathrm{Hz}$ sub-Joule fs-laser pumped neon- and nickel-like X-ray lasers”, Soft X-ray Lasers and Applications IV, Ernst E. Fill, Jorge J. G. Rocca, Editors, Proceedings of SPIE Vol. 4505, 85 - 92 (2001).

4. C. D. Macchietto, B. R. Benware, and J. J. Rocca, "Generation of millijoule-level soft-x-ray laser pulses at a 4-Hz repetition rate in a highly saturated tabletop capillary discharge amplifier", Opt. Lett. 24, 1115 - 1117 (1999).

5. B. E. Lemoff, G. Y. Yin, C. L. Gordon III, C. P. J. Barty, and S. E. Harris, "Demonstration of a 10-Hz Femtosecond-Pulse-Driven XUV Laser at 41.8 nm in Xe IX", Phys. Rev. Lett. 74, 1574 - 1577(1995)

6. S. Sebban, R. Haroutunian, Ph. Balcou, G. Grillon, A. Rousse, S. Kazamias, T. Marin, J. P. Rousseau, L. Notebaert, M. Pittman, J. P. Chambaret, A. Antonetti, D. Hulin, D. Ros, A. Klisnick, A. Carillon,P. Jaeglé, G. Jamelot, and J. F. Wyart, "Saturated Amplification of a Collisionally Pumped Optical-Field-Ionization Soft X-Ray Laser at 41.8 nm", Phys. Rev. Lett., 86, 3004 - 3007 ( 2001).

7. S. Sebban, T. Mocek, D. Ros, L. Upcraft, Ph. Balcou, R. Haroutunian, G. Grillon, B. Rus, A. Klisnick, A. Carillon, G. Jamelot, C. Valentin, A. Rousse, J. P. Rousseau, L. Notebaert, M. Pittman, and D. Hulin, "Demonstration of a Ni-Like Kr Optical-Field-Ionization Collisional Soft X-Ray Laser at $32.8 \mathrm{~nm}$ ", Phys. Rev. Lett., 89, 253901 1-4 (2002). 
8. Ph. Zeitoun, G. Faivre, S. Sebban, T. Mocek, A. Hallou, M. Fajardo, D. Aubert, Ph. Balcou, F. Burgy, D. Douillet, S. Kazamias, G. de Lacheze-Murel, T. Lefrou, S. le Pape, P. Mercere1, H. Merdji, A. S. Morlens, J. P. Rousseau, and C. Valentin, "A high-intensity highly coherent soft X-ray femtosecond laser seeded by a high harmonic beam", Nature 431, 426 - 429 (2004)

9. R. Keenan, J. Dunn, V.N. Shlyaptsev, R.F. Smith, P.K. Patel, and D.F. Price, "Efficient Pumping Schemes for High Average Brightness Collisional X-ray Lasers”, SPIE Int. Soc. Opt. Eng. Proc. 5197, 213-220 (2003).

10. V.N. Shlyaptsev, J. Dunn, S. Moon, R. Smith, R. Keenan, J. Nilsen, K.B. Fournier, J. Kuba, A.L. Osterheld, J.J.Rocca, B. Luther, Y. Wang, M. Marconi, "Numerical studies of transient and capillary X-ray lasers and their applications", SPIE Int. Soc. Opt. Eng. Proc. 5197, 221-228 (2003).

11. R.F. Smith, J. Dunn, J. Filevich, S. Moon, J. Nilsen, R. Keenan, V.N. Shlyaptsev, J.J. Rocca, J.R. Hunter, and M.C. Marconi, "Plasma conditions for improved energy coupling into the gain region of the Ni-like Pd transient collisional x-ray laser", Phys. Rev E, in press (2005).

12. J. Nilsen, B. MacGowan, L. B. DaSilva, and J. C. Moreno, "Prepulse technique for producing low-Z Ne-like x-ray lasers", Phys. Rev. A 48, 4682-4685 (1993).

13. P.V. Nickles, V.N. Shlyaptsev, M. Kalachnikov, M. Schnurer, I. Will and W. Sandner, "Short Pulse X-Ray Laser at $32.6 \mathrm{~nm}$ Based on Transient Gain in Ne-like Titanium”, Phys. Rev. Lett. 78, 2748-2751 (1997).

14. D. V. Korobkin, C. H. Nam, S. Suckewer, and A. Goltsov, "Demonstration of Soft X-Ray Lasing to Ground State in Li III", Phys. Rev. Lett. 77, 5206 - 5209 (1996).

15. R. Keenan, J. Dunn, P. K. Patel, D. F. Price, R. F. Smith, and V. N. Shlyaptsev, "High-Repetition-Rate GrazingIncidence Pumped X-Ray Laser Operating at 18.9 nm”, Phys. Rev. Lett. 94, 103901-1 - 4 (2005).

16. B. M. Luther, Y. Wang, M. A. Larotonda, D. Alessi, M. Berrill, M. C. Marconi, J. J. Rocca, and V.N. Shlyaptsev, "Saturated high-repetition-rate 18.9-nm tabletop laser in nickellike molybdenum", Opt. Lett. 30, 165 167 (2005).

17. Yu.V. Afanasiev and V.N. Shlyaptsev, "Formation of a population inversion of transitions in Ne-like ions in steady-state and transient plasmas", Sov. J. Quant. Electron. 19, 1606-1612 (1989); V.N. Shlyaptsev, P.V. Nickles, T. Schlegel, M.P. Kalashnikov, and A.L. Osterheld, "Table-top x-ray laser pumped with subnanosecond and picosecond pulses", SPIE Int. Soc. Opt. Eng. Proc. 2012, 111-118 (1993).

18. R. Keenan, J. Dunn, and V.N. Shlyaptsev, in preparation (2005).

19. J.J. Rocca, B.M. Luther, Y. Wang, M. A. Larotonda, D. Alessi, M. Berrill, C.S. Menoni, M. C. Marconi, and V.N. Shlyaptsev, "Demonstration of saturated high-repetition-rate table-top soft X-ray lasers at wavelengths down to $13.9 \mathrm{~nm}$ ", these proceedings (2005).

20. G. Pert, "Simulations of samarium and silver X-ray lasers", these proceedings (2005).

21. K. Janulewicz, J. Tümmler, G. Priebe, and P.V. Nickles, "X-ray lasers driven by low-energy picosecond laser pulses", these proceedings (2005).

22. T. Kawachi, K. Nagashima, M. Kishimoto, M. Tanaka, N. Hasegawa, Y. Ochi, M. Nishikino, H. Kawazome, K. Sukegawa, K. Namikawa, and Y. Kato, "Recent progress in X-ray laser research in JAERI", these proceedings (2005). 
